NASA/TM-2000-209045

\title{
Correlation of Electric Field and Critical Design Parameters for Ferroelectric Tunable Microwave Filters
}

Guru Subramanyam

University of Dayton, Dayton, Ohio

Fred W. Van Keuls and Félix A. Miranda

Glenn Research Center, Cleveland, Ohio

Chadwick L. Canedy, Sanjeev Aggarwal, Thirumalai Venkatesan, and Ramamoorthy Ramesh

University of Maryland, College Park, Maryland 
The NASA STI Program Office ... in Profile

Since its founding, NASA has been dedicated to the advancement of aeronautics and space science. The NASA Scientific and Technical Information (STI) Program Office plays a key part in helping NASA maintain this important role.

The NASA STI Program Office is operated by Langley Research Center, the Lead Center for NASA's scientific and technical information. The NASA STI Program Office provides access to the NASA STI Database, the largest collection of aeronautical and space science STI in the world. The Program Office is also NASA's institutional mechanism for disseminating the results of its research and development activities. These results are published by NASA in the NASA STI Report Series, which includes the following report types:

- TECHNICAL PUBLICATION. Reports of completed research or a major significant phase of research that present the results of NASA programs and include extensive data or theoretical analysis. Includes compilations of significant scientific and technical data and information deemed to be of continuing reference value. NASA's counterpart of peerreviewed formal professional papers but has less stringent limitations on manuscript length and extent of graphic presentations.

- TECHNICAL MEMORANDUM. Scientific and technical findings that are preliminary or of specialized interest, e.g., quick release reports, working papers, and bibliographies that contain minimal annotation. Does not contain extensive analysis.

- CONTRACTOR REPORT. Scientific and technical findings by NASA-sponsored contractors and grantees.
- CONFERENCE PUBLICATION. Collected papers from scientific and technical conferences, symposia, seminars, or other meetings sponsored or cosponsored by NASA.

- SPECIAL PUBLICATION. Scientific, technical, or historical information from NASA programs, projects, and missions, often concerned with subjects having substantial public interest.

- TECHNICAL TRANSLATION. Englishlanguage translations of foreign scientific and technical material pertinent to NASA's mission.

Specialized services that complement the STI Program Office's diverse offerings include creating custom thesauri, building customized data bases, organizing and publishing research results ... even providing videos.

For more information about the NASA STI Program Office, see the following:

- Access the NASA STI Program Home Page at http://www.sti.nasa.gov

- E-mail your question via the Internet to help@sti.nasa.gov

- Fax your question to the NASA Access Help Desk at 301-621-0134

- Telephone the NASA Access Help Desk at 301-621-0390

- Write to: NASA Access Help Desk NASA Center for AeroSpace Information 7121 Standard Drive Hanover, MD 21076 
NASA/TM-2000-209045

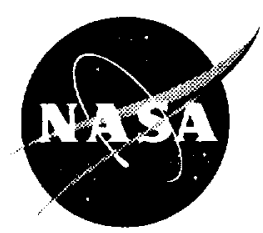

\section{Correlation of Electric Field and Critical Design Parameters for Ferroelectric Tunable Microwave Filters}

Guru Subramanyam

University of Dayton, Dayton, Ohio

Fred W. Van Keuls and Félix A. Miranda

Glenn Research Center, Cleveland, Ohio

Chadwick L. Canedy, Sanjeev Aggarwal, Thirumalai Venkatesan, and Ramamoorthy Ramesh

University of Maryland, College Park, Maryland

Prepared for the

11th International Symposium on Integrated Ferroelectrics sponsored by the University of Colorado

Colorado Springs, Colorado, March 7-10, 1999

National Aeronautics and

Space Administration

Glenn Research Center 


\section{Acknowledgments}

The work was performed at NASA Glenn Research Center, Cleveland, Ohio. The author Guru Subramanyam acknowledges the NASA/OAI Summer Faculty Research Fellowship Program. The author Fred W. Van Keuls acknowledges the National Research Council Fellowship. The authors acknowledge fabrication support offered by Mr. Nick Varaljay, Ms. Liz McQuaid, and Mr. Bruce Viergutz.

Available from

NASA Center for Aerospace Information 7121 Standard Drive Hanover, MD 21076

Price Code: A03
National Technical Information Service 5285 Port Royal Road Springfield, VA 22100 Price Code: A03 


\title{
CORRELATION OF ELECTRIC FIELD AND CRITICAL DESIGN PARAMETERS FOR FERROELECTRIC TUNABLE MICROWAVE FILTERS
}

\author{
Guru Subramanyam \\ University of Dayton \\ Dayton, Ohio 45469 \\ Fred W. Van Keuls and Félix A. Miranda \\ National Aeronautics and Space Administration \\ Glenn Research Center \\ Cleveland, Ohio 44135 \\ Chadwick L. Canedy, Sanjeev Aggarwal, \\ Thirumalai Venkatesan, and Ramamoorthy Ramesh \\ University of Maryland \\ College Park, Maryland 20742
}

The correlation of electric field and critical design parameters such as the insertion loss, frequency tunability, return loss, and bandwidth of conductor/ferroelectric/dielectric microstrip tunable K-band microwave filters is discussed in this work. This work is based primarily on barium strontium titanate (BSTO) ferroelectric thin film based tunable microstrip filters for room temperature applications. Two new parameters which we believe will simplify the evaluation of ferroelectric thin films for tunable microwave filters, are defined. The first of these, called the sensitivity parameter, is defined as the incremental change in center frequency with incremental change in maximum applied electric field $\left(E_{P E A K}\right)$ in the filter. The other, the loss parameter, is defined as the incremental or decremental change in insertion loss of the filter with incremental change in maximum applied electric field. At room temperature, the $\mathrm{Au} / \mathrm{BSTO} / \mathrm{LAO}$ microstrip filters exhibited a sensitivity parameter value between 15 and $5 \mathrm{MHz} / \mathrm{cm} / \mathrm{kV}$. The loss parameter varied for different bias configurations used for electrically tuning the filter. The loss parameter varied from 0.05 to $0.01 \mathrm{~dB} / \mathrm{cm} / \mathrm{kV}$ at room temperature. 


\section{INTRODUCTION}

Tunable microwave components based on the nonlinear electric field dependence of ferroelectric thin films such as strontium titanate $\left(\mathrm{SrTiO}_{3}\right)$ and barium strontium titanate $\left(\mathrm{Ba}_{\mathrm{x}} \mathrm{Sr}_{1-\mathrm{x}} \mathrm{TiO}_{3}\right)$ are attracting attention in the microwave research community. ${ }^{[1-5]} \mathrm{SrTiO}_{3}$, also referred to as $\mathrm{STO}$, is suitable for low temperature applications below $77 \mathrm{~K}$, as one can reduce its relative dielectric constant by more than a factor of 5 by applying a dc electric field. ${ }^{[4]} \mathrm{Ba}_{\mathrm{x}} \mathrm{Sr}_{1-\mathrm{x}} \mathrm{TiO}_{3}$, also referred to as BSTO, on the other hand, can be tailored to be a room temperature tunable ferroelectric, as one could reduce its relative dielectric constant by more than a factor of 5 at or near room temperature. ${ }^{[5]}$ Tunable resonators, bandpass filters, and phase shifters have been successfully demonstrated using thin films of these two materials in the past few years. ${ }^{[1-6]}$ Large tunability higher than $15 \%$ have been reported in tunable filters, and resonators based on the ferroelectric thin films. ${ }^{[3]}$ In addition, we have recently reported on $\mathrm{K}$-band tunable bandpass filters using conductor/ferroelectric/dielectric substrate multilayered microstrip configration. ${ }^{[6-7]}$ However, a detailed work on the effect of electric field on the important circuit parameters in ferroelectric tunable microstrip filters is still necessary. In this work, we have thoroughly analyzed the effect of the applied electric field (primarily responsible for tunability in these planar filters) on the parameters such as the insertion loss, center frequency, the return loss, and the bandwidth of the microstrip bandpass filters based on the conductor/ferroelectric/dielectric substrate multilayered microstrip configuration. The largest applied electric field is an important parameter in microstrip filters, since circuit geometries could result in unequal electric fields in different portions of the circuit. The smallest gap will have the largest electric field for a given bias, and for the purpose of this paper it is defined as the peak electric field $\left(E_{\text {peak }}\right)$. Also, $E_{\text {peak }}$ allows for better comparison between filters with different geometries. Based on the analysis, we propose two new performance evaluation parameters which we believe will be of importance for microwave applications of the ferroelectric tunable components. The first is called the sensitivity parameter, defined as the slope of the center frequency versus the $E_{\text {peak }}$ curve. The second parameter, called the loss parameter, is defined as the slope of the insertion loss versus the $E_{\text {peak }}$ curve. The sensitivity parameter is important for fine tuning the filter for the required center frequency with as minimal an applied electric field/bias as possible. Since the ferroelectrics are nonlinear dielectric materials, the sensitivity factor will also be 
varying in a nonlinear fashion. Knowing the center frequency or frequency shift versus the maximum applied electric field or the maximum and minimum sensitivity factors in the operating range of the electric field would help in fine tuning the filter's operation. The loss parameter on the other hand gives the insertion loss variability with electric field. Ideally, one would like to operate in a region where the variability of insertion loss with electric field is minimal. One may be able to reduce the insertion loss by choosing the right bias configuration, as will be demonstrated in this work.

\section{DESIGN}

The filters were designed with edge coupled half wavelength resonators for $4 \%$ bandwidth for the passband frequency range between 18.6 and 19.4 GHz. The filters were designed with $300 \mathrm{~nm}$ tunable ferroelectric thin films. The design of the 2 pole filters has been described elsewhere. ${ }^{[6,7]}$ The filter was optimized using Sonnet $\mathrm{em}^{\circledR}$ tools. $^{[8]}$ The geometry of the two pole filter is shown in Fig. 1. The filter has radial bias stubs for de biasing of each resonator section. The input and output microstrip lines were biased using custom made bias stubs. ${ }^{[9]}$ Although

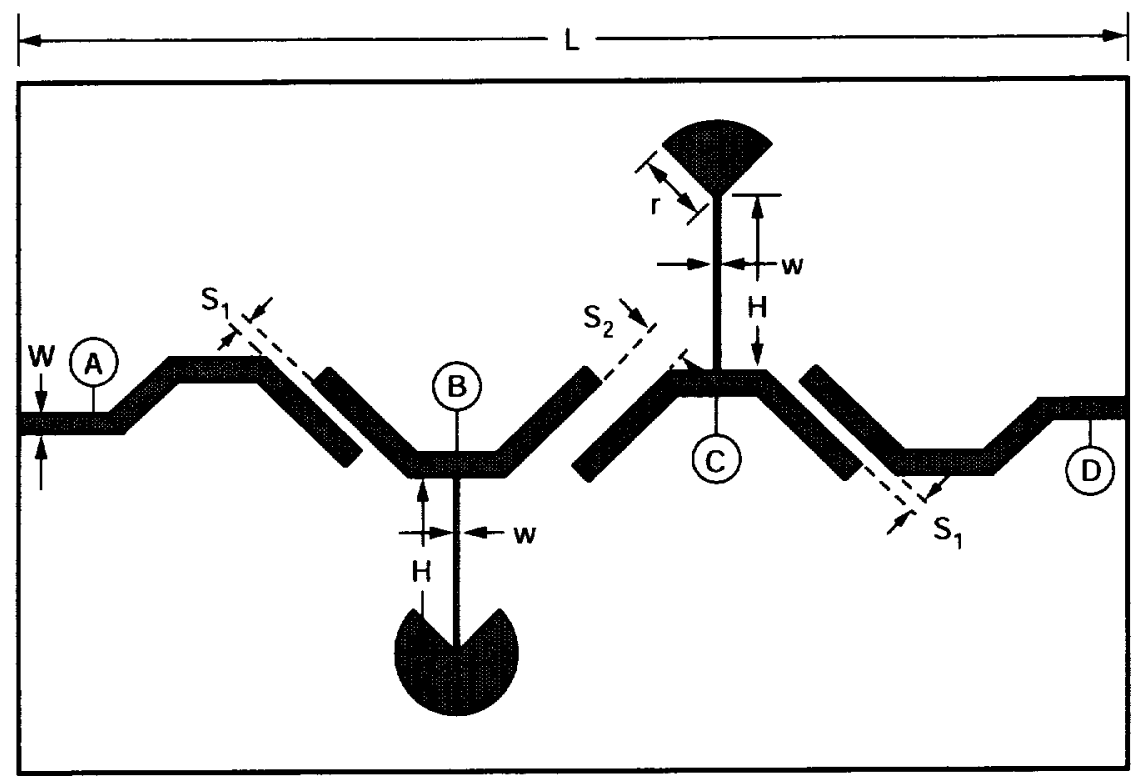

FIGURE 1. Geometry of the 2 pole microstrip tunable filter using the conductor/ ferroelectric/dielectric multilayer configuration. The dimensions are $W=86.25 \mu \mathrm{m}$, $w=12.5 \mu \mathrm{m} . \mathrm{L}=6.8 \mathrm{~mm}, \mathrm{H}=1.33 \mathrm{~mm}, \mathrm{r}=200 \mu \mathrm{m}, \mathrm{S}_{1}=100 \mu \mathrm{m}$, and $\mathrm{S}_{2}=300 \mu \mathrm{m}$. 
the design of the filters was primarily for STO ferroelectric, it is also valid for BSTO with lower tunable range of relative dielectric constant $\varepsilon_{\mathrm{rBSTO}}$. At present, the relative dielectric constant of STO $\left(\varepsilon_{\mathrm{rSTO}}\right)$ is typically tunable between 4000 and 300 at low temperatures below $77 \mathrm{~K}^{[10]}$ whereas $\varepsilon_{\mathrm{rBSTO}}$ is tunable between 2500 and 400 at room temperature. ${ }^{[5]}$ These values depend markedly upon growth conditions, film thickness, dopants, doping concentration, and temperature.

\section{EXPERIMENTAL}

The samples with BSTO thin film on $\mathrm{LaAlO}_{3}$ (LAO) substrates ferroelectric were obtained from the University of Maryland. $300 \mathrm{~nm}$ thick BSTO thin films were deposited on LAO substrates by pulsed laser deposition technique. The K-band Au/BSTO/LAO bandpass filter circuits were fabricated using standard positive photoresist lithography. The filters were studied under different bias conditions: (1) unipolar bias (UPB) where alternate nodes were biased positive, and ground, (2) partial bipolar bias (PBB) where input and output lines were grounded, and the resonator sections biased positive and negative alternatively, (3) full bipolar bias (FBB) where alternate sections (including the input and output lines) were biased positive and negative. It is important to note that the effective dielectric constant of the microstrip structure depends upon the electric field between the biased microstrip lines as well as the perpendicular field between the top conductor and the ground plane. The BSTO ferroelectric based filters were studied at room temperature and under vacuum, to eliminate any possibility of arcing at high bias voltages. Bias voltages were applied up to $\pm 400 \mathrm{~V}$, with minimal power consumption. As can be seen in Fig. 1, the smallest spacing is between the input and output coupled

sections. The maximum electric field will be across these two coupled sections compared to the coupled sections between the resonators. Swept frequency scattering parameter measurements were performed using an HP8510C automatic network analyzer (ANA).

\section{RESULTS}

The swept frequency scattering parameter measurements performed on one of the gold/BSTO/LAO based K-band microstrip bandpass filter is shown in Fig. 2. The measurements were performed at room tempera- 
ture with no bias. The minimum insertion loss of the filter has a minimum of $6.9 \mathrm{~dB}$, which is primarily due to the higher loss tangent $(\tan \delta)$ in BSTO thin films in the range of 0.01-0.1 at room temperature. ${ }^{[5]}$ The bias dependent frequency tunability of the filter measured at room temperature for (a) partial bipolar and (b) full bipolar configuration are shown in Fig. 3. As seen in the figures, the partial bipolar configuration is definitely improving the insertion loss of the filter, whereas the full bipolar configuration maintains the passband flat, with minimal ripple. In general, the full bipolar configuration gives the largest frequency tunability

\begin{tabular}{|ll|}
\hline MARKER 1 & \\
$18.307 \mathrm{GHz}$ & \\
$\mathrm{S}_{11}$ & $\mathrm{~S}_{12}$ \\
$-9.3354 \mathrm{~dB}$ & $-7.5327 \mathrm{~dB}$ \\
& $\mathrm{~S}_{22}$ \\
$\mathrm{~S}_{21}$ & $-9.7739 \mathrm{~dB}$ \\
$-6.9133 \mathrm{~dB}$ & \\
\hline
\end{tabular}
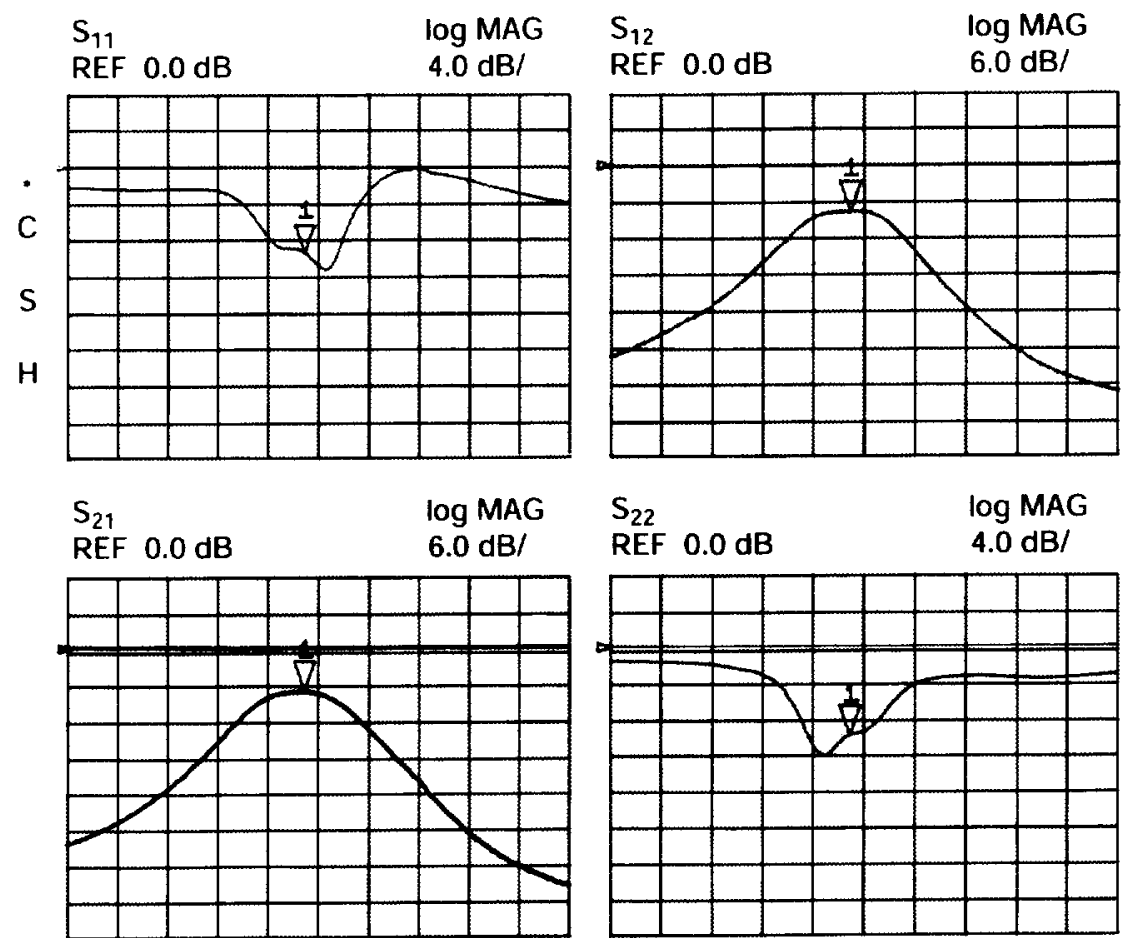

Start $15.0 \mathrm{GHz}$

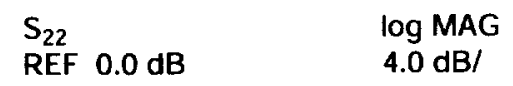

FIGURE 2. The swept frequency s-parameter measurements performed on a $\mathrm{Au} / \mathrm{BSTO} / \mathrm{LAO}$ filter at room temperature. 


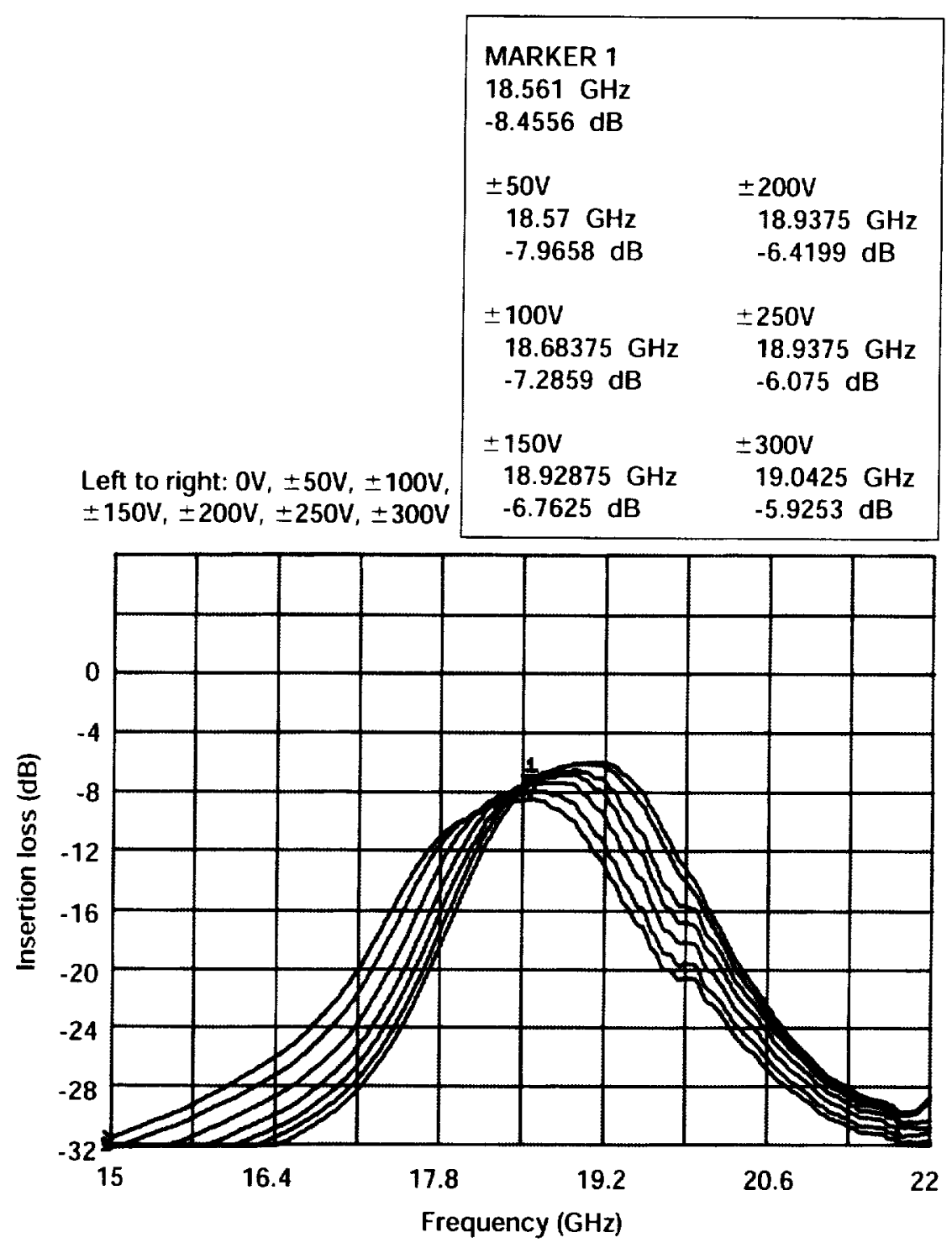

FIGURE 3a. The bias dependence of the same BSTO fitter for a partial bipolar configuration. 

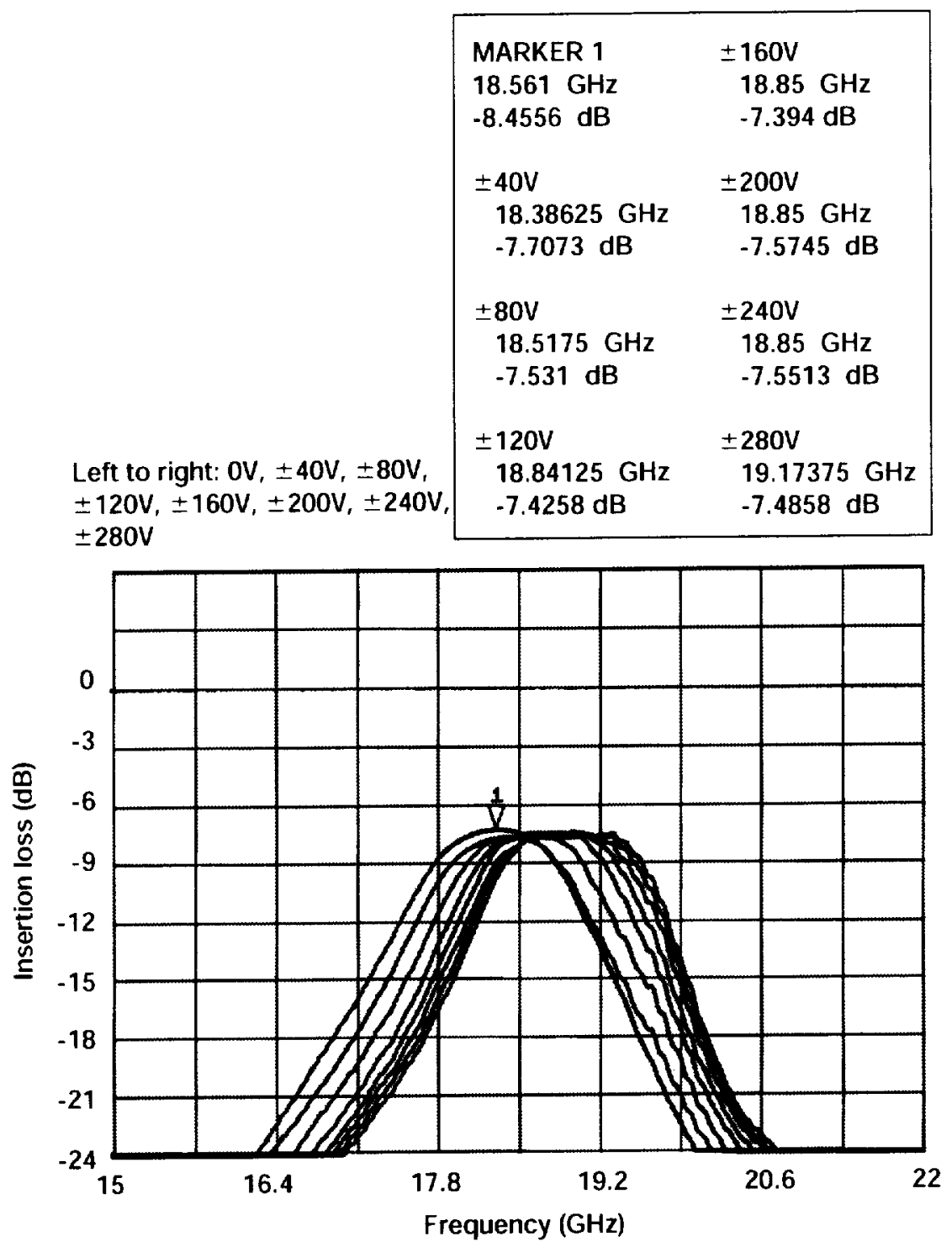

FIGURE 3b. The bias dependence of the same BSTO filter for a full bipolar configuration. 
due to higher electric fields that can be applied in this configuration, and the partial bipolar gives the lowest insertion loss in the passband in the $\mathrm{Au} / \mathrm{BSTO} / \mathrm{LAO}$ filters. The center frequency versus $\mathrm{E}_{\text {peak }}$ is shown in Fig. 4 for the same filter. One can obtain the sensitivity parameter as the slope of the center frequency versus $E_{\text {peak }}$ characteristics. It is evident that there are three distinct regions $(8-16,20-36$, and $42-56 \mathrm{kV} / \mathrm{cm})$ where the slopes of the characteristics are changing with the magnitude of the $\mathrm{E}_{\text {peak }}$. There appears to be a threshold $\mathrm{E}_{\text {peak }}$ necessary, approximately $4 \mathrm{kV} / \mathrm{cm}$, before the tunability is more pronounced. Also, between the three regions identified above, there appears to be transition regions. The origin for these transition regions is still under investigation. For the filter under discussion, the sensitivity parameter is approximately $15 \mathrm{MHz} / \mathrm{cm} / \mathrm{kV}$ at fields between $8-16 \mathrm{kV} / \mathrm{cm}$ and reduces to $5 \mathrm{MHz} / \mathrm{cm} / \mathrm{kV}$ at fields above $44 \mathrm{kV} / \mathrm{cm}$, for measurements taken at room temperature. For comparison, the sensitivity parameter varies from 31 to $15 \mathrm{MHz} / \mathrm{cm} / \mathrm{kV}$ for (gold, HTS)/STO/LAO based filters at $77 \mathrm{~K}$ and is greater than $100 \mathrm{MHz} / \mathrm{cm} / \mathrm{kV}$ at $24 \mathrm{~K}$ for fields below $20 \mathrm{kV} / \mathrm{cm}$. In general, we have observed that the sensitivity parameter is the highest at electric fields below $20 \mathrm{kV} / \mathrm{cm}$ in most samples tested to date.

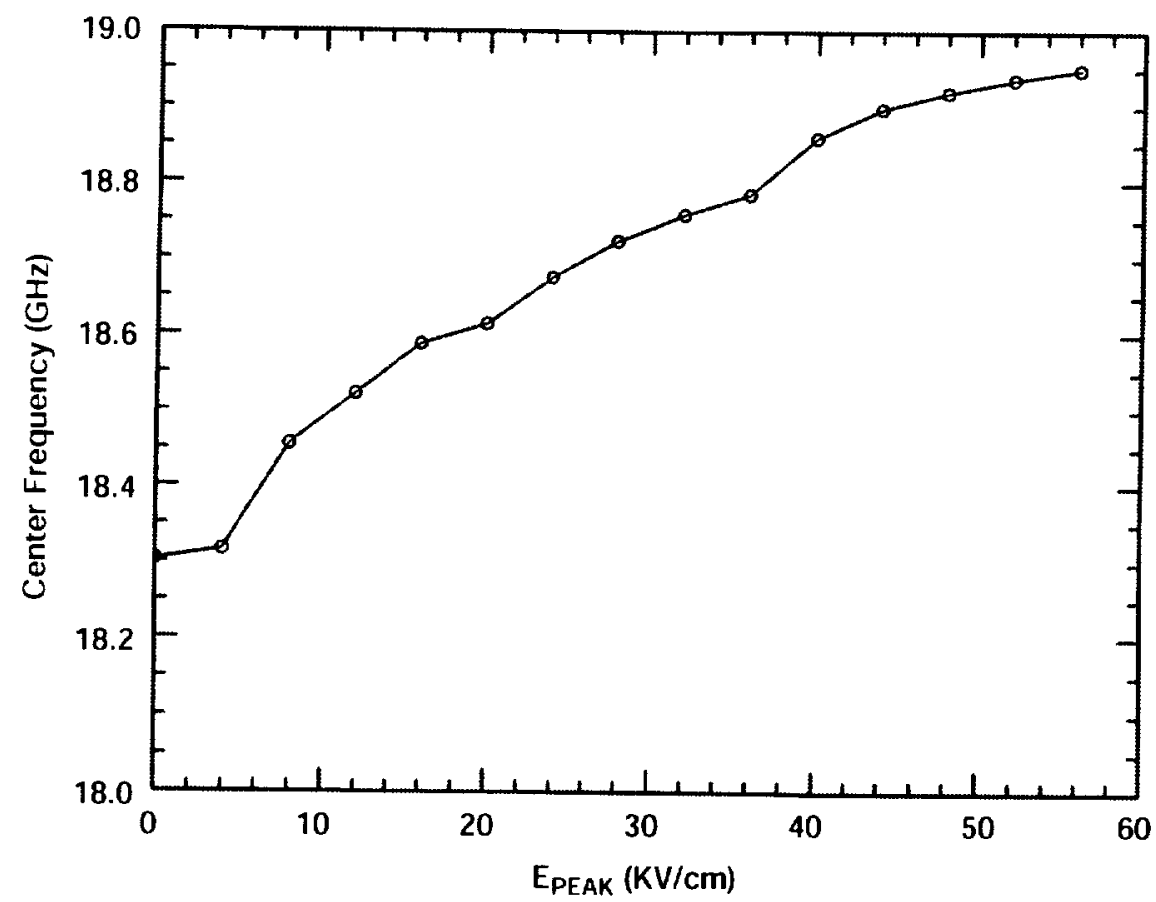

FIGURE 4. The electric field dependence of the center frequency of the filter for the full bipolar configuration. 
Figure 5 shows the insertion loss and return loss versus $E_{\text {peak }}$ for one of the Au/BSTO/LAO tunable filters tested at room temperature, using the partial bipolar bias configuration. We define the loss parameter as the slope of the insertion loss versus $\mathrm{E}_{\text {peak }}$ characteristics. What is evident from the figure is that there are two regions one in which there is a large change in insertion loss, greater than $0.6 \mathrm{~dB}$ (between 10 and $36 \mathrm{kV} / \mathrm{cm}$ ) and the other in which the insertion loss varies less than $0.1 \mathrm{~dB}$, above $36 \mathrm{kV} / \mathrm{cm}$. Depending upon the design requirements one could choose to operate in the region where the insertion loss variation is low or in a region where the insertion loss could be reduced to the lowest level possible. Note that the insertion loss remains a constant at fields above $36 \mathrm{kV} / \mathrm{cm}$. The return loss on the other hand, decreases to its lowest value around $44 \mathrm{kV} / \mathrm{cm}$. This result is contrary to conventional microstrip filters, as the insertion loss should be improving with lower return losses. Similar results have been observed in STO ferroelectric tunable filters as well. The reason for constant insertion loss with improving return loss could possibly be due to additional losses in the ferroelectric thin film at these high fields. As can be seen from Figs. 4 and 5, large tunability at low fields below $20 \mathrm{kV} / \mathrm{cm}$ does not necessarily give the lowest insertion

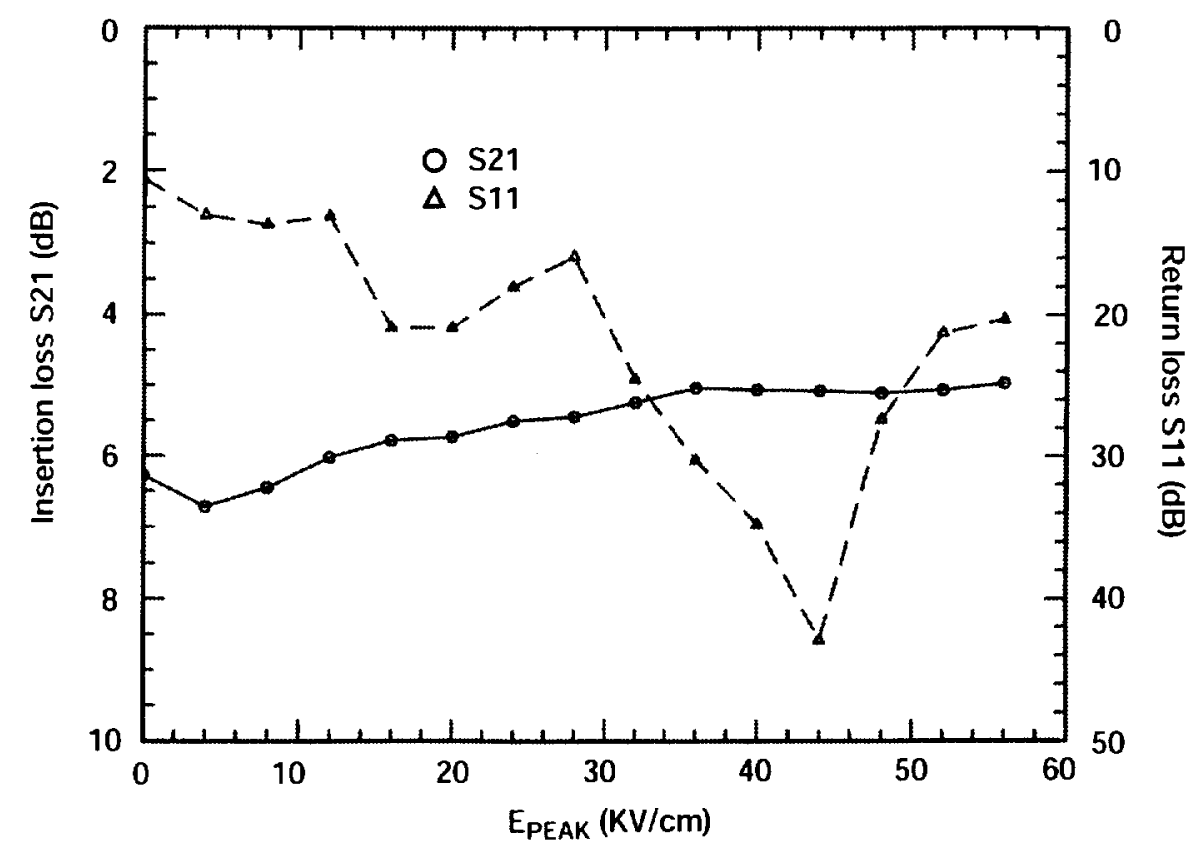

FIGURE 5. The electric field dependence of the insertion loss and return loss for the same filter, measured at room temperature under the partial bipolar bias configuration. The full bipolar configuration maintains the passband insertion loss almost constant throughout the tunning range, as in figure $3 \mathrm{~b}$. 
loss for the filters. The loss factor varies from $-0.02 \mathrm{~dB} / \mathrm{cm} / \mathrm{kV}$ at fields below $20 \mathrm{kV} / \mathrm{cm}$ to $-0.005 \mathrm{~dB} / \mathrm{cm} / \mathrm{kV}$ at high fields above $40 \mathrm{kV} / \mathrm{cm}$. It is evident from Fig. 5 that the return loss is below $-20 \mathrm{~dB}$ between 30 and $50 \mathrm{kV} / \mathrm{cm}$ of $\mathrm{E}_{\text {peak }}$. Figure 6 shows the electric field dependence of bandwidth for the same BSTO based 2 pole filter. The bandwidth reduces from $1350 \mathrm{MHz}(7 \%)$ to approximately $1200 \mathrm{MHz}(6 \%)$ at low fields below $20 \mathrm{kV} / \mathrm{cm}$ and increases to approximately $1500 \mathrm{MHz}(8 \%)$ at higher fields. The BSTO based filters allow a frequency tunability of approximately 200 to $300 \mathrm{MHz}$ below $20 \mathrm{kV} / \mathrm{cm}$ at room temperature, a factor of 5 smaller than the best STO based filter circuit operating at $77 \mathrm{~K} \cdot{ }^{[7]}$

\section{DISCUSSIONS}

A critical finding from this work, one which we believe will have an impact on the use of ferroelectric thin films in tunable filters is that the sensitivity parameter remains almost the same for each sample, irrespec-

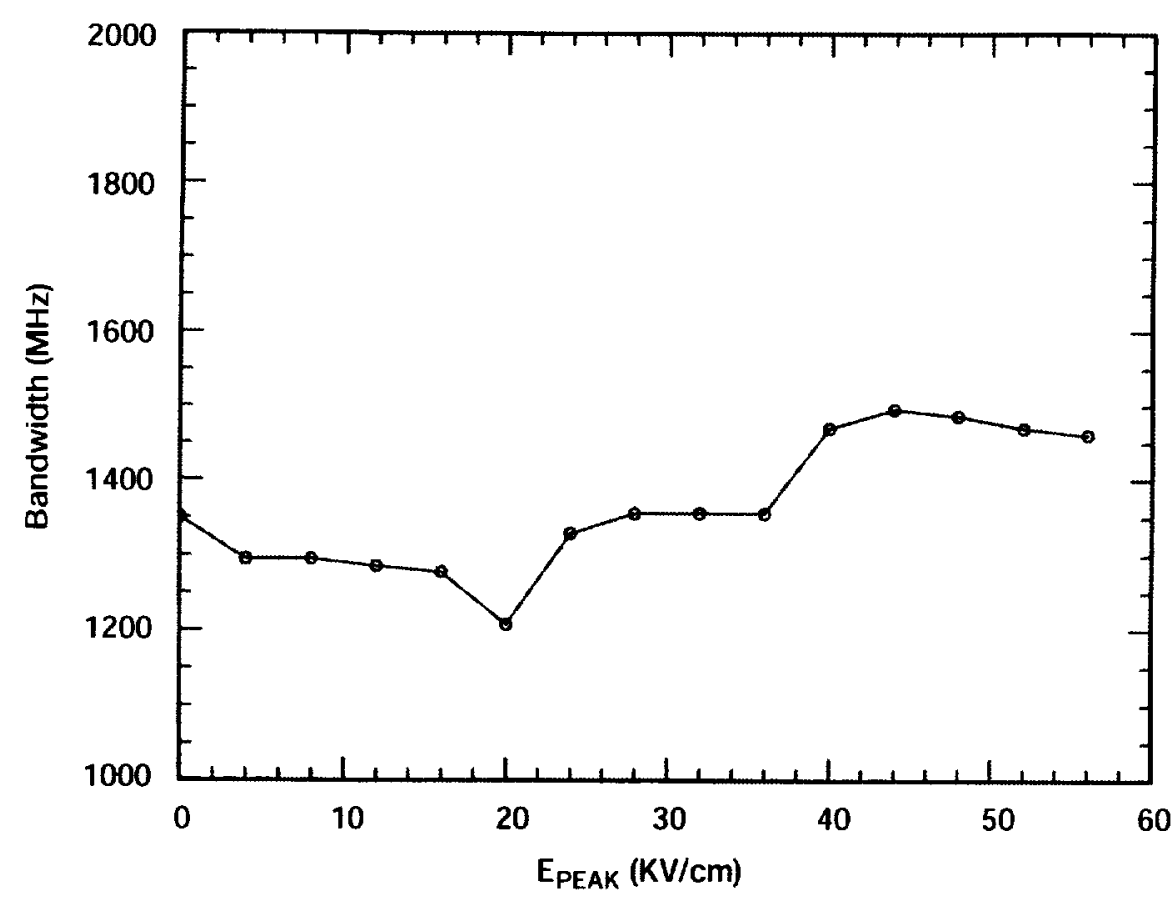

FIGURE 6. The electric field dependence of the passband bandwidth of the same filter at room temperature under the full bipolar bias configuration. 
tive of the bias configuration employed. Figure 7 shows the frequency shift versus $E_{\text {peak }}$ for two different samples. Remarkably, the sensitivity parameter remains very much the same at low fields below $20 \mathrm{kV} / \mathrm{cm}$ for the three different bias configurations defined earlier in this paper. This is a significant result since evaluation of the ferroelectric materials can be accomplished using the sensitivity parameter and the loss parameter, when used in tunable microstrip filters. Ideally, a ferroelectric material should yield a low loss parameter and a high sensitive parameter, for highly reliable tunable filters. As shown in Fig. 7, the sensitivity parameter of sample 1 is higher than that of sample 2.

For the practical applicability of these filters, the manufacturers should give the typical values of low field $(<=20 \mathrm{kV} / \mathrm{cm})$ and high field $(>20 \mathrm{kV} / \mathrm{cm})$ sensitivity parameters, and loss parameters. In addition, the typical electric field or bias voltage dependence of the important parameters such as the center frequency, minimum insertion loss in the passband, return loss, the passband ripple, and bandwidth of the filter will allow the users to choose the optimum filter's response based on the design requirements.

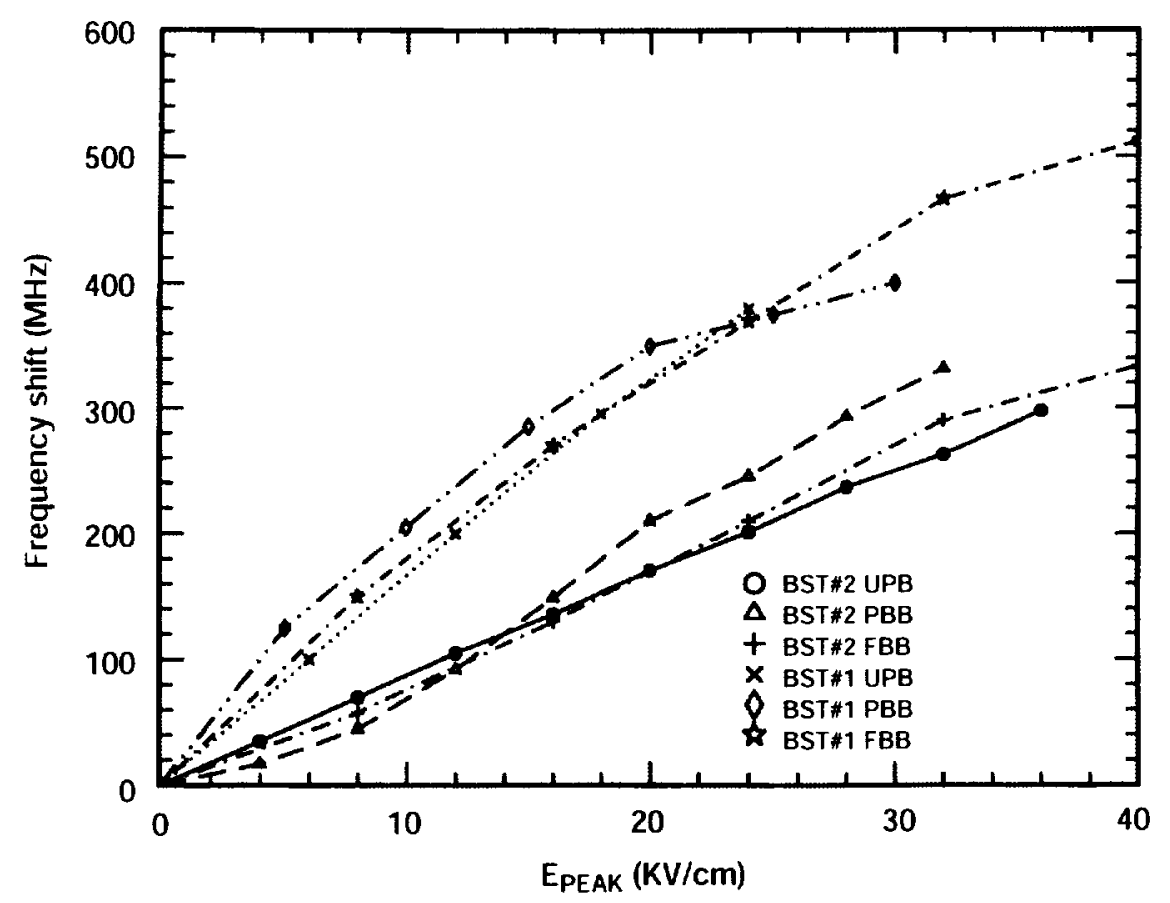

FIGURE 7. The electric field dependence of the frequency shift in two different samples of Au/BSTO/LAO filters. The sensitivity parameter in sample 1 is higher than the sensitivity parameter in sample 2 . 


\section{SUMMARY AND CONCLUSIONS}

Room temperature tunable BSTO ferroelectric based microstrip filters using the $\mathrm{Au} / \mathrm{BSTO} / \mathrm{LAO}$ configuration have been fabricated and tested using different bias configurations. The correlation of electric field with the important design parameters such as the insertion loss, return loss, center frequency, and the bandwidth of the filters were studied. Based on our study, we propose two new parameters, which may be important for the applicability of the ferroelectric tunable filters. The sensitivity parameter is defined as the incremental change in the center frequency for incremental change in $\mathrm{E}_{\text {peak }}$. The sensitivity parameter varies between 15 and $5 \mathrm{MHz} / \mathrm{cm} / \mathrm{kV}$ at room temperature, with largest sensitivity parameters observed below $20 \mathrm{kV} / \mathrm{cm}$, typically. The loss parameter is defined as the incremental/decremental change in the insertion loss for incremental change in $E_{\text {peak }}$. The loss parameter varies from $-0.02 \mathrm{~dB} / \mathrm{cm} / \mathrm{kV}$ at fields below $20 \mathrm{kV} / \mathrm{cm}$ to $-0.005 \mathrm{~dB} / \mathrm{cm} / \mathrm{kV}$ at high fields above $40 \mathrm{kV} / \mathrm{cm}$.

\section{References}

[1.] D.G. Vendik, L.T. Ter-Martiosyan, A.I. Dedyk, S.F. Karmanenko, and R.A. Chakalov, "High Tc superconductivity applications of ferroelectrics at microwave frequencies," Ferroelectrics, 144, p. 33 (1993).

[2.] A.M. Hermann, R.M. Yandrofski, J.F. Scott, A. Nazirpour, D. Galt, J.C. Price, J. Cuchario, and R.K. Ahrenkiel, "Oxide superconductors and ferroelectrics-materials for a new generation of tunable microwave devices," J. of Superconductivity, 7, no. 2, p. 463 (1994).

[3.] A.T. Findikoglu, X. Jia, X.D. Wu, G.J. Chen, T. Venkatesan, and D.W. Reagor, "Tunable and adaptive bandpass filter using a nonlinear dielectric thin film of STO," Appl. Phys. Lett., 68, no. 12, (1996).

[4.] F.A. Miranda, R.R. Romanofsky, F.W. Van Keuls, C.H. Mueller, R.E. Treece, and T.V. Rivkin, "Thin film multilayer conductor/ ferroelectric tunable microwave components for communication applications," Integrated Ferroelectrics, 17, p. 231 (1997).

[5.] F.A. Miranda, F.W. Van Keuls, R.R. Romanofsky, and G. Subramanyam, "Tunable microwave components for $\mathrm{Ku}$ - and K-band satellite communications," Integrated Ferroelectrics, 22 , p. 269 (1998). 
[6.] G. Subramanyam, F.W. Van Keuls, and F.A. Miranda, "A K-band tunable microstrip bandpass filter using a thin film conductor/ ferroelectric/dielectric multilayer configuration," IEEE Microwave and Guided wave lett., 8, no. 2, p. 78 (1998).

[7.] G. Subramanyam, F.W. Van Keuls, and F.A. Miranda, "A novel K-band tunable microstrip bandpass filter using a thin film HTS/ ferroelectric/dielectric multilayer configuration," IEEE MTT-S International Microwave Symposium Digest, 2, p. 1011 (1998).

[8.] Sonnet em ${ }^{\circledR}$ users manuals, Sonnet Software Inc., Liverpool, NY.

[9.] R.R. Romanofsky, "Custom bias tees for X to K-band applications," unpublished.

[10.] D.M. Dalbert, R.E. Stauber, J.C. Price, C.T. Rogers, and D. Galt, "Improved low frequency and microwave dielectric response in strontium titanate thin films grown by pulsed laser ablation," Appl. Phys. Lett., 72, no. 4, p. 507 (1998). 
Public reporting burden for this collection of information is estimated to average 1 hour per response, including the time for reviewing instructions, searching existing data sources, gathering and maintaining the data needed, and completing and reviewing the collection of information. Send comments regarding this burden estimate or any other aspect of this coilection of information. including suggestions for reducing this burden, to Washington Headquarters Services. Directorate for Information Operations and Reports, 1215 jefferson Davis Highway, Suite 1204, Artington, VA 22202-4302, and to the Otfice of Management and Budget, Paperwork Reduction Project (0704-018B). Washington, DC 20503.

\begin{tabular}{l|l|l} 
1. AGENCY USE ONLY (Leave blank) & 2. REPORT DATE
\end{tabular} 3. REPORT TYPE AND DATES COVERED

4. TITLE AND SUBTITLE

November 2000

Technical Memorandum

Correlation of Electric Field and Critical Design Parameters

for Ferroelectric Tunable Microwave Filters

6. AUTHOR(S)

WU-755-08-0B-00

Guru Subramanyam, Fred W. Van Keuls, Félix A. Miranda, Chadwick L. Canedy,

Sanjeev Aggarwal, Thirumalai Venkatesan, and Ramamoorthy Ramesh

7. PERFORMING ORGANIZATION NAME(S) AND ADDRESS(ES)

National Aeronautics and Space Administration

John H. Glenn Research Center at Lewis Field

Cleveland, Ohio 44135-3191

8. PERFORMING ORGANIZATION REPORT NUMBER

E-11576

9. SPONSORING/MONITORING AGENCY NAME(S) AND ADDRESS(ES)

10. SPONSORING/MONITORING AGENCY REPORT NUMBER

National Aeronautics and Space Administration

Washington, DC 20546-0001

NASA TM-2000-209045

\section{SUPPLEMENTARY NOTES}

Prepared for the 11 th International Symposium on Integrated Ferroelectrics sponsored by the University of Colorado, Colorado Springs, Colorado, March 7-10, 1999. Guru Subramanyam, University of Dayton, Dayton, Ohio 45469: Fred W. Van Keuls and Félix A. Miranda. NASA Glenn Research Center; Chadwick L. Canedy, Sanjeev Aggarwal. Thirumalai Venkatesan, and Ramamoorthy Ramesh. University of Maryland, College Park, Maryland 20742. Responsible person, Felix A. Miranda, organization code 5620, 216-433-6589.

12a. DISTRIBUTIONAVAILABILITY STATEMENT 12b. DISTRIBUTION CODE

Unclassified - Unlimited

Subject Category: 33

Distribution: Nonstandard

This publication is available from the NASA Center for AeroSpace Information, 301-621-0390.

13. ABSTRACT (Maximum 200 words)

The correlation of electric field and critical design parameters such as the insertion loss, frequency tunability, return loss, and bandwidth of conductor/ferroelectric/dielectric microstrip tunable $\mathrm{K}$-band microwave filters is discussed in this work. This work is based primarily on barium strontium titanate (BSTO) ferroelectric thin film based tunable microstrip filters for room temperature applications. Two new parameters which we believe will simplify the evaluation of ferroelectric thin films for tunable microwave filters, are defined. The first of these, called the sensitivity parameter, is defined as the incremental change in center frequency with incremental change in maximum applied electric field $\left(E_{P E A K}\right)$ in the filter. The other, the loss parameter, is defined as the incremental or decremental change in insertion loss of the filter with incremental change in maximum applied electric field. At room temperature, the Au/BSTO/LAO microstrip filters exhibited a sensitivity parameter value between 15 and $5 \mathrm{MHz} / \mathrm{cm} / \mathrm{kV}$. The loss parameter varied for different bias configurations used for electrically tuning the filter. The loss parameter varied from 0.05 to $0.01 \mathrm{~dB} / \mathrm{cm} / \mathrm{kV}$ at room temperature.

14. SUBJECT TERMS

Electronics devices; Ferroelectrics; Filters; Ferroelectric thin-films; Microwave frequencies; Microstrip lines; Tunable bandpass filters

\begin{tabular}{|c|c|}
\hline $\begin{array}{c}\text { 17. SECUAITY CLASSIFICATION } \\
\text { OF REPORT } \\
\text { Unclassified }\end{array}$ & $\begin{array}{c}\text { 18. SECURITY CLASSIFICATION } \\
\text { OF THIS PAGE } \\
\text { Unclassified }\end{array}$ \\
\hline
\end{tabular}

19. SECURITY CLASSIFICATION OF ABSTRACT

Unclassified

\section{NUMBER OF PAGES}

19

16. PRICE CODE

$\mathrm{A03}$

20. LIMITATION OF ABSTAACT

Standard Form 298 (Rev. 2-89) Prescribed by ANSI Std. Z39-18
$298-102$ 
